\title{
Impact of Obesity on Ureteroscopic Laser Lithotripsy of Urinary Tract Calculi
}

\author{
Ricardo Natalin, Keith Xavier, Zephaniah Okeke, Mantu Gupta
}

Department of Urology, Columbia University, College of Physicians and Surgeons, New York, NY, USA

\begin{abstract}
Purpose: The treatment of urinary tract stones in obese patients may differ from the treatment of non-obese patients and their success rate varies. Our objective was to compare ureteroscopic treatment outcomes of ureteral and renal stones, stratified for stone size and location, between overweight, obese and non-obese patients.

Materials and Methods: Charts were reviewed for 500 consecutive patients presenting at our institution for renal and ureteral stones. A total of 107 patients underwent flexible or semi-rigid ureteroscopy with Ho:YAG laser lithotripsy and met criteria for review and analysis.

Results: Overall, initial stone-free rates were 91\%, 97\%, and 94\% in normal, overweight and obese individuals respectively. When compared to non-obese patients, there were no significant differences ( $p$ value $=0.26 ; 0.50$ ). For renal and proximal ureteral stones, the stone-free rate in overweight and obese individuals was $94 \%$ in both groups; and a stone-free rate of $100 \%$ was found for distal stones, also in both groups.

Conclusions: Ureteroscopic treatment of stones in obese and overweight patients is an acceptable treatment modality, with success rates similar to non-obese patients.
\end{abstract}

Key words: ureter; calculi; ureteroscopy; Ho-YAG Laser; obesity

Int Braz J Urol. 2009; 35: 36-42

\section{INTRODUCTION}

Obesity has become a major health problem in the United States and the world and represents a chronic disease mediated by genetics, environment, metabolism, psychosocial causes, cultural, and physiologic variables (1). The prevalence of obesity in the United States has increased by approximately $30 \%$ from 1980 to 1994 (2). The most common method of defining obesity is the Body Mass Index (BMI). BMI measures the height to weight ratio by taking weight in kilograms and dividing it by height in squared meters $\left(\mathrm{kg} / \mathrm{m}^{2}\right)$. According to the World Health Organization guidelines, a BMI of 18.5 to $25 \mathrm{~kg} / \mathrm{m}^{2}$ is considered normal, overweight is a BMI of 25 to 29.9 , obese is a $\mathrm{BMI} \geq 30$, and morbidly obese is a $\mathrm{BMI} \geq 40$ (3).

Various lithogenic risk factors are known to be associated with obesity and increase the chance of stone formation in these patients as hyperinsulinemia, increased BMI, hyperoxaluria, high sodium intake, low urinary volume and hypercalciuria. Duffey et al. found that $98 \%$ of obese patients had at least one lithogenic risk factor in a 24-hour urine sample and $80 \%$ of them had 3 or more factors (4).

Extracorporeal shock wave lithotripsy (ESWL) has emerged as the primary treatment of 
choice for renal calculi less than $1.5-2 \mathrm{~cm}$ (5). ESWL has been recommended as first-line treatment of ureteral calculi less than $1 \mathrm{~cm}$, resulting in up to a $92.6 \%$ stone free rate for proximal stones and $97.5 \%$ for mid and distal ones (6). However, obese patients are fraught with difficulties in treating calculi by ESWL and may not have these same high success rates as in non-obese patients. Delakas et al. reported an increased chance of ESWL failure in obese patients of 1.9 fold when BMI was $>30$, and Muñoz et al. found a $72 \%$ stone free rate after ESWL for these patients $(7,8)$. In these obese patients, a frequent factor limiting the success of ESWL is positioning the patient so the stone can be located at the focal point of the lithotripter. Most lithotripters have a maximum skin to stone distance of $12-14 \mathrm{~cm}$ for their focal point, which can restrict the depth in which stone fragmentation can be accomplished (9). For this reason, ESWL for obese patients may be a sub-optimal treatment.

PCNL as a potential treatment for renal calculi in obese patients can also be difficult. This is due to an increased distance that needs to be traversed in order to obtain the correct access into a calyx, making percutaneous access more difficult. Also, even if access is obtained, normal size instruments may not be able to be used and longer instruments including nephroscope and access sheath may be required in an obese patient. Another potential problem during PCNL in an obese patient is the increased anesthetic complication risk that can ensue from the patient being in the prone position for a long period of time.

For these previously mentioned reasons, rigid and flexible ureteroscopy is most likely the treatment of choice for urinary calculi in obese patients. The development of small caliber ureteroscopes and advances in intracorporeal lithotripsy, such as ultrasound, electrohydraulic waves, laser, and most recently the holmium: yttrium-aluminum-garnet (Ho:YAG) laser, have permitted more successful and safer endoscopic manipulation of ureteral calculi (10). In order to ascertain whether ureteroscopy is more effective in obese patients, we compared outcomes data, stratified for stone size and location, in overweight, obese, morbidly obese and normal weight patients as defined by BMI.

\section{MATERIALS AND METHODS}

Charts were reviewed for 500 consecutive patients treated for renal and/or ureteral calculi at our institution over a five-year period. Inclusion criteria for the study included all patients with radio-opaque calculi who were treated ureteroscopically, in combination with Ho:YAG laser lithotripsy, as primary therapy. Indications for treatment were calculi that did not pass spontaneously or required earlier intervention because of recurrent colic or obstruction of the upper urinary tract. Patients who had contraindications such as pregnancy, urinary tract infection, coagulation disorders, or previous ureteral reimplantation were excluded from the study. After a thorough review, 107 patients met the criteria for this review.

Ureteroscopy was performed in combination with Ho:YAG laser lithotripsy by the same surgeon (M.G.) using a small caliber (6F) semi-rigid or flexible ureteroscope.

Distal stones were treated via a Wolf semirigid ureteroscope with a $6 \mathrm{~F}$ self-dilating tip and for proximal ureteral stones we used the flexible ureteroscope Storz Flex-X or ACMI DUR-8 or DUR-8 Elite, depending on availability. No dilation of the ureteral orifice was necessary because of self-dilating tip ureteroscope (for distal stones). For proximal stones, ureteral access sheath was placed underneath the stone (Cook Flexor, $35 \mathrm{~cm}$ ), with size varying from 9 to $11 \mathrm{~F}$ when using Storz Flex-X and from 12 to $14 \mathrm{~F}$ when using ACMI ureteroscope.

Our standard technique for ureteroscopic treatment of ureteral calculi includes cystoscopy with retrograde pyelogram, placement of a 0.038 -inch floppy-tipped guide wire past the stone (glidewire when necessary) to maintain access, placement of a safety wire for flexible ureteroscopy, and ureteroscopy with Ho:YAG laser lithotripsy. Continuous irrigation and/or intermittent manual pumping of irrigant to obtain a clear ureteroscopic view were used where appropriate. For ureteroscopic laser lithotripsy, a Ho: YAG laser (Trimedyne, Inc., Irvine, CA) was employed. The Ho:YAG laser operates at a wavelength of 2100-nm and the laser frequency was usually set between $5-10 \mathrm{~Hz}$ and a power of 5-10 W. Higher settings were used to treat harder calculi. The vast majority of the patients were treated with a $200 \mathrm{uH}$ 
quartz fiber. Basket retrieval of stone fragments was employed when necessary. Patients received general anesthesia at the beginning of the procedure.

A preoperative $\mathrm{x}$-ray of the kidneys, ureters, and bladder were done in all patients, and excretory urogram (IVP), non-contrast helical computer tomography, or sonogram were done when indicated to document the size and location of the stone. Patients were postoperatively imaged with radiographs, noncontrast helical computer tomography, and/or IVP until they were stone-free or received additional treatment ( 0 to 3 months). A patient was considered stone free when post operative imaging revealed fragments of $2 \mathrm{~mm}$ or less. Characteristics of patient age, sex, stone size and location, operative time, and treatment outcome were recorded and tabulated. Average patient age and mean stone size were similar for all groups (Table-1).

Treatment outcomes were defined as radiographic evidence of fragmentation or complete disappearance of the stone. Retreatment and additional procedures were also registered. All procedures were performed on an outpatient basis.

For each of the treatment groups, 95\% confidence intervals were calculated for the overall treatment success rates. Statistical comparison of two independent percentages was done by means of the Fisher's exact test (2-sided, $p=0.05)$. If the result- ing $p$ value was $<0.05$, the difference in the sample percentages was considered statistically significant.

\section{RESULTS}

The average patient age and mean stone size were similar for all groups (Table-2). Mean operating time was 70.37 minutes for normal weight individuals, 88.78 minutes for overweight persons, 78.23 minutes for obese patients. These differences were not statistically significant between groups (Table-1).

Indications for the procedure were due to persistent pain despite analgesic medication in 51 patients, obstruction with ultrasound revealing hydronephrosis in 24 and persistent pain associated with evidence of obstruction in 32 .

The initial stone-free rate for ureteral calculi $1 \mathrm{~cm}$ or greater following treatment with ureteroscopy with Ho:YAG laser lithotripsy was $93 \%$. For ureteral calculi less than $1 \mathrm{~cm}$, the initial stone-free rate was $100 \%$.

Stratified for location (Table-1), the initial stone free rates for renal/ proximal ureteral stones ranged from $93 \%$ to $100 \%$ for all weight categories. The small numbers of patients ( 7 patients in total, 1 failure) with mid-ureteral stones had stone free rates that varied from $67 \%$ to $100 \%$. For distal ureteral

Table 1 - Outcomes.

\begin{tabular}{lccc}
\hline & Normal & Overweight & Obese \\
\hline Operation time (minutes) & 70.37 & 88.78 & 78.23 \\
$\quad$ Range & $30-170$ & $30-159$ & $30-156$ \\
$\quad \mathrm{p}$ Value & & 0.16 & 0.36 \\
Stone free (N) & 31 & 38 & 32 \\
$\quad$ Failure & 3 & 1 & 2 \\
$\quad \mathrm{p}$ Value & & 0.26 & 0.5 \\
Stone free (\%) & $91 \%$ & $97 \%$ & $94 \%$ \\
$\quad$ Location & & & \\
$\quad$ Renal / Proximal ureter & $93 \%$ & $94 \%$ & $94 \%$ \\
$\quad$ Mid ureter & $100 \%$ & $100 \%$ & $67 \%$ \\
$\quad$ Distal ureter & $90 \%$ & $100 \%$ & $100 \%$ \\
\hline
\end{tabular}


Table 2 - Patient characteristics.

\begin{tabular}{lccc}
\hline & Normal & Overweight & Obese \\
\hline $\mathrm{N}$ & 34 & 39 & 34 \\
Age & 46.93 & 51.26 & 53.32 \\
Gender & & & \\
$\quad$ Male & 9 & 20 & 21 \\
$\quad$ Female & 25 & 19 & 13 \\
BMI & 22.74 & 27.32 & 33.6 \\
$\quad$ Range & $7.82-24.85$ & $25.10-29.75$ & $30.13-45.55$ \\
Laterality & & & 19 \\
$\quad$ Right & 19 & 24 & 15 \\
$\quad$ Left & 15 & 15 & 6 \\
Location & 1 & & 14 \\
$\quad$ Renal & 11 & 0 & 2 \\
$\quad$ Proximal ureter & 3 & 15 & 12 \\
$\quad$ Mid ureter & 17 & 2 & 0.81 \\
$\quad$ Distal ureter & 0.9 & 0.8 & 18 \\
Average size $(\mathrm{cm})$ & 20 & 21 & 16 \\
$\quad<1$ cm & 14 & 18 & \\
$\quad$ cm or greater & & & \\
\hline
\end{tabular}

stones, the initial success rates ranged from $90 \%$ to $100 \%$. Neither stone size nor location appeared to influence the efficacy of ureteroscopic treatment, since no significant difference was observed in the stone free rates between patients with ureteral calculi $1 \mathrm{~cm}$ or greater and those with calculi less than $1 \mathrm{~cm}$.

Failures were due to proximal migration of stone with inability to retrieve all fragments from lower pole in 3 patients and to residual fragments left in the ureter that failed to spontaneously pass to the bladder in other 3 patients. No intraoperative or postoperative complications occurred in any of the groups.

\section{COMMENTS}

When ESWL cannot be used or is not an appropriate treatment option in the obese patient, the next option is often ureteroscopy or percutaneous nephrolithotomy (PCNL). El-Assmy et al. showed that PCNL in obese patients was not only safe but that obese patients did not experience any difference in success, operative time, or morbidity (11). Even though good results can be obtained PCNL in the obese patient it still presents many challenges to the urologist. The substantial amount of subcutaneous fat and increased mobility of the kidney secondary to excess fat in the retroperitoneum make instrument access more difficult. Also, sometimes standard PCNL equipment is not long enough and extra-long equipment (nephroscope, etc.) has to be used in the obese patient, making the procedure technically more difficult. Ureteroscopic laser lithotripsy and stone extraction has been shown to be an effective method for treating urolithiasis in morbidly obese patients who were too large for ESWL (12). Compared to in situ ESWL, ureteroscopic lithotripsy appears to be more effective in the treatment of proximal ureteral calculi $1 \mathrm{~cm}$ or greater.

Recent technological advances, especially in the field of optics, have allowed endoscopes to become smaller, more flexible, and easier to introduce. Prior to the development of small caliber ureteroscopes, the stone-free rates achieved with ureteroscopy for distal ureteral calculi using large diameter rigid ureteroscopes 
(more than $10 \mathrm{~F}$ ), ultrasonic lithotriptors, or electro hydraulic lithotriptors with probes larger than $3 \mathrm{~F}$, was greater than $90 \%(12,13)$. However, for mid-ureteral calculi, it was in the range of $60 \%$, and for proximal calculi, close to $50 \%$ (13). More recent contemporary series, using small diameter rigid and flexible endoscopes as well as laser lithotriptors, have reported success rates of greater than $90 \%$ for proximal ureteral calculi (13). In our experience, the initial overall stonefree rate after ureteroscopic laser lithotripsy of proximal ureteral calculi was $97 \%$, with a stone-free rate of $93 \%$ for calculi $1 \mathrm{~cm}$ or greater, which is consistent with the success rates of other reported series.

The introduction of the Ho:YAG laser has improved ureteroscopy stone-free rates while decreasing the risk of complications, and thus has been employed for lithotripsy by many groups with encouraging results. The Ho:YAG laser can fragment all types of calculi, including hard calcium oxalate monohydrate and cystine stones, by delivering energy through small-diameter quartz fibers that can be used through the working channels of the smallest available ureteroscopes. It fragments stones with an ablative effect, removing portions of the stone as dust-like particles during the fragmentation procedure. This process allows for the treatment of large calculi within the upper urinary tract without the burdensome process of fragment removal. The safety and efficacy of the Ho:YAG laser as an endoscopic lithotripter has been confirmed in other studies $(14,15)$.

Our results show that it is possible to achieve stone-free status even in obese patients when treating them with ureteroscopy. Our results in fact showed higher stone-free rates in patients with a BMI of greater than 25 , although the rates are virtually the same. One limitation of the study is the small number of patients in the morbidly obese group. Based on these results, ureteroscopy with laser lithotripsy should be given serious consideration in any obese patient with a stone smaller than $2 \mathrm{~cm}$. With the continued improvement in technology and scopes, the potentially more difficult access to the ureter of obese patients, due to body habitus reasons, can be easier overcome and stone-free rates can approach or be equivalent to that of non-obese patients.

Long-term complication rates of ureteroscopy range from 0.5 to $10 \%$ for larger caliber instruments
(16). Complications are rare with small caliber instruments. Our low overall complication rate was consistent with those reported by other series. The majority of cases may be treated without ureteral dilation and have a lower likelihood of ureteral trauma. Thus, routine ureteral stenting following ureterscopy and intracorporeal lithotripsy may not be necessary, thereby decreasing morbidity $(17,18)$.

\section{CONCLUSIONS}

Our study demonstrates that ureteroscopy is an acceptable treatment modality for all ureteral calculi and may be preferable to ESWL for obese patients. By using small caliber ureteroscopes and Ho:YAG laser lithotripsy, the target stone could be treated safely and effectively in our patients. In overweight and obese patients, results are comparable to non-obese patients. These results presented are independent of stone size and location.

\section{CONFLICT OF INTEREST}

None declared.

\section{REFERENCES}

1. Pasulka PS, Bistrian BR, Benotti PN, Blackburn GL: The risks of surgery in obese patients. Ann Intern Med. 1986; 104: 540-6.

2. Willett WC, Dietz WH, Colditz GA: Guidelines for healthy weight. N Engl J Med. 1999; 341: 427-34.

3. Stevens J, Cai J, Pamuk ER, Williamson DF, Thun MJ, Wood JL: The effect of age on the association between body-mass index and mortality. N Engl J Med. 1998; 338: 1-7.

4. Duffey BG, Pedro RN, Kriedberg C, Weiland D, Melquist J, Ikramuddin S, et al.: Lithogenic risk factors in the morbidly obese population. J Urol. 2008; 179: 1401-6.

5. Jamshaid A, Ather MH, Hussain G, Khawaja KB: Single center, single operator comparative study of the effectiveness of electrohydraulic and electromagnetic lithotripters in the management of 10 - to $20-\mathrm{mm}$ single upper urinary tract calculi. Urology. 2008; 72 : 991-5. 
6. Murota-Kawano A, Ohya K, Sekine H: Outpatient basis extracorporeal shock wave lithotripsy for ureter stones: efficacy of the third generation lithotripter as the first line treatment. Int J Urol. 2008; 15: 210-5.

7. Delakas D, Karyotis I, Daskalopoulos G, Lianos E, Mavromanolakis E: Independent predictors of failure of shockwave lithotripsy for ureteral stones employing a second-generation lithotripter. J Endourol. 2003; 17: 201-5.

8. Muñoz RD, Tirolien PP, Belhamou S, Desta M, Grimberg R, Dulys P, et al.: Treatment of reno-ureteral lithiasis with ESWL in obese patients. Apropos of 150 patients. Arch Esp Urol. 2003; 56: 933-8.

9. Calvert RC, Burgess NA: Urolithiasis and obesity: metabolic and technical considerations. Curr Opin Urol. 2005; 15: 113-7.

10. Preminger GM, Tiselius HG, Assimos DG, Alken P, Buck AC, Gallucci M, et al.: 2007 Guideline for the management of ureteral calculi. Eur Urol. 2007; 52: 1610-31.

11. El-Assmy AM, Shokeir AA, El-Nahas AR, Shoma AM, Eraky I, El-Kenawy MR, et al.: Outcome of percutaneous nephrolithotomy: effect of body mass index. Eur Urol. 2007; 52: 199-204.

12. Nguyen TA, Belis JA: Endoscopic management of urolithiasis in the morbidly obese patient. J Endourol. 1998; 12: 33-5.
13. Anderson KR, Keetch DW, Albala DM, Chandhoke PS, McClennan BL, Clayman RV: Optimal therapy for the distal ureteral stone: extracorporeal shock wave lithotripsy versus ureteroscopy. J Urol. 1994; 152: 62-5.

14. Jiang $\mathrm{H}, \mathrm{Wu} \mathrm{Z}$, Ding Q: Ureteroscopy and holmium: YAG laser lithotripsy as emergency treatment for acute renal failure caused by impacted ureteral calculi. Urology. 2008; 72: 504-7.

15. Farkas A, Péteri L, Lorincz L, Salah MA, Flaskó T, Varga A, et al.: Holmium:YAG laser treatment of ureteral calculi: A 5-year experience. Lasers Med Sci. 2006; 21: 170-4.

16. Elashry OM, Elgamasy AK, Sabaa MA, Abo-Elenien M, Omar MA, Eltatawy HH, et al.: Ureteroscopic management of lower ureteric calculi: a 15-year singlecentre experience. BJU Int. 2008; 102: 1010-7.

17. Ibrahim HM, Al-Kandari AM, Shaaban HS, Elshebini YH, Shokeir AA: Role of ureteral stenting after uncomplicated ureteroscopy for distal ureteral stones: a randomized, controlled trial. J Urol. 2008; 180: 9615.

18. Cheung MC, Lee F, Yip SK, Tam PC: Outpatient holmium laser lithotripsy using semirigid ureteroscope. Is the treatment outcome affected by stone load? Eur Urol. 2001; 39: 702-8.
Accepted after revision: November 10, 2008

\section{Correspondence address:}

Dr. Mantu Gupta

Dept of Urology, Columbia University

Irving Pavilion, 11th Floor

161 Ft. Washington Avenue

New York, NY, 10032, USA

Fax: + 1212 342-6870

E-mail: guptama@pol.net

\section{EDITORIAL COMMENT}

Obesity has become a major health problem in the world. Various lithogenic risk factors are associated with obesity, increasing the chance of stone formation in these patients.
The surgical treatment of kidney and ureteral stones in morbidly obese patients remains difficult because shockwave lithotripsy may be a sub-optimal treatment due to weight limitations and percutaneous 
nephrolithotomy is associated with difficult access, anesthetic complications and a high rate of transfusion (1).

Dash et al. showed in a matched comparison (obese x normal) that ureteroscopic (URS) treatment of renal calculi when matched for location and size is as successful as and no more morbid in morbidly obese than in normal weight patients. URS treatment of renal calculi is a safe and effective first-line treatment for renal calculi in morbidly obese patients (2).

The authors study demonstrates that ureteroscopy is an acceptable treatment modality for all ureteral calculi and may be preferable to ESWL for obese patients.
The development of small caliber ureteroscopes and advances in intracorporeal lithotripsy have allowed for more successful and safer endoscopic manipulation of renal/ureteral calculi in overweight, obese, and morbidly obese patients.

\section{REFERENCES}

1. Andreoni C, Afane J, Olweny E, Clayman RV: Flexible ureteroscopic lithotripsy: first-line therapy for proximal ureteral and renal calculi in the morbidly obese and superobese patient. J Endourol. 2001; 15: 493-8.

2. Dash A, Schuster TG, Hollenbeck BK, Faerber GJ, Wolf JS Jr: Ureteroscopic treatment of renal calculi in morbidly obese patients: a stone-matched comparison. Urology. 2002; 60: 393-7; discussion 397.

Dr. Mauricio Rubinstein Federal Univ. of State of Rio de Janeiro UNIRIO

Rio de Janeiro, RJ, Brazil E-mail:mrubins@attglobal.net

\section{EDITORIAL COMMENT}

The authors present their experience with ureteroscopic laser lithotripsy in obese and morbidly obese patients. The conclusion is that obesity is not a hindrance and results are similar with those obtained in non-obese patients.

Some articles have been published on the outcome of percutaneous nephrolithotomy in this group of patients and showed that results are comparable to those obtained in non-obese (1-3). This is the first article addressing specifically ureteroscopy in obese and results are encouraging. Since the results of extracorporeal shock wave lithotripsy in these patients are not as good as in non-obese, ureteroscopy could be considered the first line approach even in proximal ureteral stones. As obesity represents a worldwide public health problem an owing to its relationship with urolithasis, articles comparing the various forms of treating stones in obese are welcome.

\section{REFERENCES}

1. Bagrodia A, Gupta A, Ramon SD, Bensalah K, Pearle MS, Lotan Y: Impact of body mass index on cost and clinical outcome after percutaneous nephrostolithotomy. Urology. 2008: 29 (In press).

2. El-Assmy AM, Shokeir AA, El-Nahas AR, Shoma AM, Eraky I, El-Kenawy MR, et al.: Outcome of percutaneous nephrolithotomy: effect of body mass index. Eur Urol. 2007; 52: 199-204.

3. Nguyen TA, Belis JA: Endoscopic management of urolithiasis in the morbidly obese patient. J Endourol. 1998; 12: 33-5.

\author{
Dr. Eduardo Mazzucchi \\ Division of Urology \\ University of Sao Paulo, USP \\ Sao Paulo, SP, Brazil \\ E-mail:mazuchi@terra.com.br
}

